\title{
Refuge
}

Canada's Journal on Refugees

Revue canadienne sur les réfugiés

\section{Refugees, Higher Education, and Informational Barriers}

\section{Jaswant Kaur Bajwa, Sidonia Couto, Sean Kidd, Roula Markoulakis, Mulugeta Abai and Kwame McKenzie}

Volume 33, Number 2, 2017

URI: https://id.erudit.org/iderudit/1043063ar

DOI: https://doi.org/10.7202/1043063ar

See table of contents

Publisher(s)

Centre for Refugee Studies, York University

ISSN

0229-5113 (print)

1920-7336 (digital)

Explore this journal

Cite this article

Bajwa, J., Couto, S., Kidd, S., Markoulakis, R., Abai, M. \& McKenzie, K. (2017). Refugees, Higher Education, and Informational Barriers. Refuge, 33(2), 56-65. https://doi.org/10.7202/1043063ar

\section{Article abstract}

The purpose of the qualitative study was to explore the experiences, needs, barriers, and expectations of survivors of torture and/or war, interested in entering post-secondary education in Canada. We conducted 38 interviews with participants from the Canadian Centre for Victims of Torture (CCVT), 10 interviews with CCVT staff, and 1 focus group with 3 participants, which followed a semi-structured interview guide, and were analyzed using a constant comparative method. Survivors of torture and/or war report experiencing informational barriers to navigating educational pathways, accessing professional supports, evaluating credentials, financing education, navigating immigration systems, using online resources, delaying their educational progress, and contributing to mental health distress.
Copyright (c) Refuge: Canada's Journal on Refugees, 2017

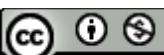

This document is protected by copyright law. Use of the services of Érudit (including reproduction) is subject to its terms and conditions, which can be viewed online.

https://apropos.erudit.org/en/users/policy-on-use/ 


\title{
Refugees, Higher Education, and Informational Barriers
}

\author{
JASWANT KAUR BAJWA, SIDONIA COUTO, SEAN KIDD, ROULA MARKOULAKIS, \\ MULUGETA ABAI, AND KWAME MCKENZIE
}

\section{Abstract}

The purpose of the qualitative study was to explore the experiences, needs, barriers, and expectations of survivors of torture and/or war, interested in entering post-secondary education in Canada. We conducted 38 interviews with participants from the Canadian Centre for Victims of Torture (CCVT), 10 interviews with CCVT staff, and 1 focus group with 3 participants, which followed a semi-structured interview guide, and were analyzed using a constant comparative method. Survivors of torture and/or war report experiencing informational barriers to navigating educational pathways, accessing professional supports, evaluating credentials, financing education, navigating immigration systems, using online resources, delaying their educational progress, and contributing to mental health distress.

\section{Résumé}

Lobjectif de cette étude qualitative était détudier les expériences, les besoins, les obstacles et les attentes de survivants à la torture et/ou à la guerre souhaitant faire des études postsecondaires au Canada. Nous avons réalisé 38 entretiens avec des participants provenant du Centre Canadien pour Victimes de la Torture (CCVT) et 10 entretiens avec des membres du personnel de ce centre; nous avons également travaillé avec un groupe cible de trois participants qui ont suivi les consignes d'un guide d'entretien semi-structuré et ont été évalués à l'aide d'une méthode comparative constante. Les survivants à la torture et/ou à la guerre ont fait état d'obstacles à type de manque d'information sur l'orientation dans les filières détudes, l'accès à des soutiens professionnels, l'évaluation des diplômes, le financement des études, l'orientation dans les systèmes d'immigration et l'utilisation des ressources en ligne, l'ensemble de ces insuffisances retardant leur progression sur le plan des études et contribuant à des difficultés de santé mentale.

\section{Background}

Refugees experience lower rates of access to post-secondary education in Canada, in comparison to other newcomers. ${ }^{1}$ Research demonstrates that refugee youth struggle during secondary school, ${ }^{2}$ while older refugees are more likely to drop out of secondary and post-secondary education than Canadian-born students, or students who immigrate to Canada as children. ${ }^{3}$ This lack of access to higher education contributes to limited social and economic mobility, or downward occupational mobility, leaving many refugees experiencing unemployment, underemployment, and lower incomes, in comparison to other newcomers. ${ }^{4}$ This is problematic, as the experience of living in poverty can negatively contribute to refugees' mental health outcomes and lead to social exclusion, further limiting successful settlement in their host country. ${ }^{5}$

Refugees are an integral part of the social fabric of Canadian life, and investing in efforts to increase their educational attainment benefits the wider Canadian society, as educated populations are better able to contribute to the social and economic growth of a country. ${ }^{6}$ Attaining higher education plays a pivotal role in the integration and inclusion of refugees into Canadian society, as it can have "wide ramifications for individual refugees, the refugee community, and the 
general common good," 7 and can result in expanded concrete skills, increased empowerment, increased confidence, and community building. ${ }^{8}$

\section{Refugees and Barriers to Post-secondary Education}

Although refugees may have high educational aspirations, many experience barriers in accessing post-secondary education. 9 Although immigrants also experience settlement barriers, refugees' complex pre-migration, migration, and post-migration experiences present unique challenges. While immigrants decide to migrate for economic or familial reasons, refugees are forced to flee their countries of origin out of humanitarian concerns, leaving behind their homes, possessions, family, and friends. ${ }^{10}$ Immigrants are generally able to prepare for their migration, research educational or employment trajectories, and have financial and familial resources to rely on. ${ }^{11}$ Alternatively, refugees are generally not able to make preparations, often have little to no familial or social support, and may not receive adequate resettlement information about Canadian society after arrival. ${ }^{12}$ This lack of preparation and support can make refugees vulnerable to informational barriers. Indeed, refugees describe having limited access to accurate and reliable information and guidance on navigating the educational system. ${ }^{13}$ Refugees also report receiving unclear and conflicting information, which reduces their access and results in disappointment and anger. ${ }^{14}$ In addition, as the result of Canada's policies and requirements for economic immigrants, many arrive with English/French fluency and significant educational attainment. ${ }^{15}$ Alternatively, refugees may experience a lack of English/French fluency and difficulty navigating the Internet, making it challenging to access information required for educational and career decisions. ${ }^{16}$ Lack of English fluency also influences success, as research based in Alberta demonstrates that despite English language learners' motivations, they are less prepared for the literacy demands of first-year university, graduate from university with lower GPAs, and take more semesters to complete their studies than native English speakers. ${ }^{17}$ Finally, although immigrants and refugees may both experience difficulties accrediting their previous education experiences, refugees express struggles in accessing educational and identification documents from their countries of origin, which are required for post-secondary education applications. ${ }^{18}$

The mental health of refugees also affects access to information. Unlike most newcomers, refugees' pre-migration and migration experiences may have included detention, torture, war, the disappearance and murder of family and friends, living in refugee camps, exploitation, and a lack of food, medicine, or housing. ${ }^{19}$ Refugees may also experience post-migration traumas in Canada, which immigrants are less likely to face, such as immigration detention, a lack of family reunification, and uncertainty about their immigration status. ${ }^{20}$ Given these stressors, refugees may experience vulnerable mental health and cognitive concerns that affect their learning, including insomnia, flashbacks, and problems with memory, concentration, and processing information. ${ }^{21}$ Refugees who are survivors of torture may experience mental health concerns, such as post-traumatic stress disorder, anxiety, and depression. ${ }^{22}$ In addition, the experience of torture can degrade survivors' self-esteem and sense of agency and control, which could affect the ability to overcome educational barriers. ${ }^{23}$

\section{Study Objective}

Scant research has examined the experiences of survivors of torture and/or war in accessing post-secondary education. This article stems from a larger community-based participatory research project conducted through a unique partnership between George Brown College (GBC), a socially inclusive post-secondary institution, the Centre for Addiction and Mental Health (САмн), a world-leading research organization, and the Canadian Centre for Victims of Torture (CCVT), a community organization working to enhance the settlement and integration of survivors in Toronto, Canada. The project's objective was to identify how post-secondary institutions can support community groups in advancing the educational goals and social inclusion of survivors of torture and/or war. To meet this aim, this project consisted of three phases: (1) exploration of the experiences, needs, barriers, and expectations of survivors of torture and/or war, (2) development of innovative programming intended to address the higher education needs and goals of survivors, and (3) pilot implementation of an educational program, offered to survivors through GBC, designed to facilitate refugees' entry into the Canadian post-secondary education environment. More specifically, this article seeks to examine the initial results from the first phase of the project conducted in fall 2015, concerning the ways in which informational barriers affect refugees' access to Canadian post-secondary education.

\section{Methods}

\section{Study Design and Sample}

This study was a community-based participatory action research partnership between GBC, CAMH, and CCVT and consisted of three distinct phases spread over two years. Community-based participatory research (СвPR) was the chosen method, as it is a framework that focuses on supporting community partners in conducting research that is meaningful to them, so that the research is driven by and mobilized back into the community. ${ }^{24}$ Although the project consists of three phases, this article will focus on the first 
phase: a qualitative exploration of the experiences, needs, barriers, and expectations of CCVT clients, who are survivors of torture and/or war, regarding pursuing post-secondary education in Canada.

All study processes and materials received institutional research ethics approval. Past and current CCVT clients were recruited for participation in the study, through flyers in CCVT's offices and shared spaces, and via CCVT staff during in-person visits, support groups, word-of-mouth, and e-mail distribution. CCVT staff were also invited to participate in the study. The majority of the recruitment was conducted within CCVT, because the centre is the only agency in Toronto that specializes in providing trauma-informed mental health and settlement support to survivors of torture and/or war. However, flyers were shared with other refugee-serving agencies via e-mail and word-of-mouth, and some participants, who were also survivors, were recruited in this manner.

Participants had the option of participating in a one-onone semi-structured interview, or a focus group, in English or French. All interviews were conducted in English, except for one conducted in French and translated into English. A focus group was held for three Tamil-speaking participants, and translated into English. Participants were provided with a 25-dollar honorarium. Since survivors of torture and/or war often have concerns about confidentiality and experience mistrust of systems, due to past experiences of state violence, efforts were made to enhance participants' sense of privacy and security. Participants were not requested to disclose detailed demographic information for this phase of the research. Efforts were made to attract representation from many refugee groups, as CCVT service providers advertised to linguistic communities they served (Amharic, Arabic, Dari, Farsi, French, Somali, Spanish, Tamil, and Tigrinya).

Consistent with a grounded theory approach, an interview guide was developed by a research steering committee, consisting of representatives from GBC, CAMH, CCVT, and three CCVT clients, and was refined as data collection proceeded, to reflect findings and explore emerging themes. Research assistants were recruited from the GBC student body, trained on conducting qualitative interviews and focus groups, and on cultural sensitivity and lay knowledge pertinent to the participant population. The interview guide consisted of questions intended to identify the unique needs of survivors of torture and/or war in accessing higher education, their experiences with services and systems in the process of accessing higher education, the gaps in addressing their needs and supporting their goals, the type of support they would benefit from to attain post-secondary education, their perspectives on the meaning of education, and beliefs or expectations regarding the opportunities afforded by educational attainment.

\section{Data Analysis}

Data collection continued until theoretical saturation was reached. ${ }^{25}$ The interviews were digitally recorded and transcribed verbatim. A constant comparative method was used, as data were analyzed simultaneously with data collection, through constant comparison of emerging and existing findings. ${ }^{26}$ Research assistants and the research steering committee met to discuss emerging ideas and interpretations of interviews conducted to that point. Subsequent interviews were informed by these meetings, as the group identified areas that required greater exploration, and attempted to bridge gaps in the data.

When transcriptions were completed, data analysis continued as the research steering committee and research assistants conducted open coding of the same sample of interview transcripts, to identify emerging properties and dimensions in the data, and create an initial codebook. Codes were added and defined until the codebook was finalized and then provided to the research assistants to code all the transcripts. Axial coding was then conducted, allowing for themes and connections to be made, and to identify specific codes related to the informational barriers that participants experienced, such as barriers to accessing professional supports and to navigating educational pathways. Once core themes and concepts were identified, selective coding further explained participants' experiences in encountering barriers, the impact of these barriers, and participants' support needs. ${ }^{27}$ Throughout the data analysis, analytic memos were also used to record ideas and reflections that arose from the transcripts, and these ideas were discussed within the research committee team meetings, enabling members to provide feedback about the connections between various informational barriers and participants' support needs, ensuring investigator triangulation. ${ }^{28}$

\section{Results}

Thirty-eight survivors of torture and/or war and 10 CCVT service providers participated in semi-structured one-onone interviews, and 3 Tamil-speaking survivors of torture and/or war participated in a focus group, bringing the total number of participants to 51. All were over 18 years of age. Detailed demographic information of participants was not collected, to enhance participants' sense of security. Nevertheless, participants represented various categories such as age groups, genders, sexual orientations, languages, length of time in Canada, and countries of origin as participants were from Central and South America, Africa, the Middle East, and Asia. CCVT service providers also represented various communities, as many were fluent in languages specific to refugee communities (Amharic, Arabic, Dari, Farsi, French, Somali, Spanish, Tamil, and Tigrinya). Out of the 41 client 
participants, 18 were men and 23 were women. The majority of participants were under the age of 40 . Some did speak English or French upon arrival to Canada, others had lower English levels and were upgrading their language skills via LINC classes or adult high school courses, while 3 participants required interpretation to participate in the research study. Participants who spoke English were at Canadian Language Benchmark Levels 5, 6, or 7 . The majority of participants had been in Canada for one to five years, and a smaller group had been in the country for less than one year.

All participants involved in the study had completed secondary school, either in their country of origin or in Canada. Many had also completed or started post-secondary programs in their country of origin. Of those that had completed degrees, participants had diverse educational backgrounds (examples include nursing, engineering, business, etc.), and many had been employed in those fields in their country of origin. Some had experienced gaps in their primary, secondary, or post-secondary education, due to war/torture or fear of persecution and being forced to flee their country of origin as a result. After arriving in Canada, some had their education interrupted as they encountered challenges in regularizing their status, or in assessing their credentials. These gaps ranged from several months to several years. The participants in the study also had diverse educational goals in Canada, some of whom wanted to attain degrees to continue in their field in Canada, others wanted to attain degrees in different educational disciplines that they had studied in their country of origin, while some sought to pursue technical/diploma training.

Our analysis identified various themes in the types of informational barriers that survivors of torture and/or war experience when trying to access post-secondary education, the impact of these barriers, and the types of supports that may be needed to mitigate some of these barriers.

\section{Informational Barriers}

\section{Navigating Educational Pathways}

Many participants reported that they lack information about how to navigate educational pathways. This included a lack of information on what types of secondary school and/or post-secondary education programs are available to them and for what purpose, what requirements they must meet in order to pursue post-secondary education, how to apply to post-secondary education, which institutions are better suited to their needs, the differences between private and public post-secondary institutions, what educational options they have to continue in the professional careers they had in their country of origin, and how future employment might be linked to their educational choices. Both CCVT staff and participants also described how clients may have difficulty with navigating the form-filling required to apply to postsecondary education programs. One participant shared the challenge of trying to start pursuing education in Canada: "You don't know where to begin. As we say, we face a lot of challenges. We don't know who to approach for the first time."

This was also evident during interviews, as many participants asked the research assistants for educational advice. This pointed to an interest and enthusiasm for education, while also suggesting that participants had minimal access to formal supports to help them make decisions about their education.

\section{Access to Professional Support}

Some participants explained that they had accessed helpful professional support, from both social service and education service providers, which guided them in the appropriate direction. For example, some participants explained that their shelter or settlement workers referred them to college upgrading programs or adult secondary schools; that they met with secondary school guidance counsellors or academic advisors at post-secondary institutions who informed them of program options, that they attended education fairs, or took tours of post-secondary campuses.

However, many other participants reported that they received unreliable, unhelpful, or inaccurate guidance, from social service, education, and government institutions. They sometimes met with providers at secondary and post-secondary institutions with little knowledge, who were not able to give advice on courses that participants should pursue. As one participant described it, "So, I talked to a counsellor [at adult secondary school], I don't know whether she was a counsellor, but she was the one in charge of the registering, about the next courses which I will be taking for the next quad. So, she told me 'I don't think you need the diploma, I think you only need those credits,' but she looked like she wasn't sure."

Another participant shared the experience of attaining limited support from the government income support office, about how to continue in a professional field:

Sometimes information available at [government social assistance services] is for basic jobs, and not for professionals needing education support. The people at the government, they don't give that much information at all. The only thing they say is, "We can help you if you are unemployed, we can get you a course for one year, and you can do hair dressing or something like that." It's a survival job. But there is not any centre like that "OK, you people who come with this degree," they check the degree, and then say, "oK, this is the field, these are the ways, the options. Which one do you want to do?"” 
Others described how they received misinformation from post-secondary institutions, how their immigration status affected their ability to study in Canada. Participants reported being commonly mistaken for international students by post-secondary institutions, despite having appropriate immigration paperwork (convention refugee or permanent resident status) demonstrating they were domestic students.

\section{Reliance on Word-of-Mouth}

Participants reported that it was common to attain information about accessing post-secondary education via word-ofmouth, through friends, family, and community members. They gathered advice on what types of upgrading and/or educational programs to pursue, the quality of educational institutions, evaluating international credentials, applying for study permits, and navigating the educational system. Some participants found this guidance useful in directing their decision-making.

Alternatively, other participants described how their reliance on word-of-mouth made them vulnerable to misinformation, and they had difficulty understanding what information was valid and what may be relevant for them on the basis of their own situations and immigration status. Many also felt confused by the differing word-of-mouth messages they received: "So I've had a challenge of ... been thinking a lot and people have been telling me, so I have a too many ideas in my head and don't know exactly what to do, because I've been getting advice from different kinds of people-not really counsellors, just people who have been here, yeah, fellow [people of home country], yeah. And they have been advising, "Do this," "Do that," "Do that."

\section{Credential Evaluation}

Some participants with professional qualifications in their country of origin described a lack of transparency about how their educational history and credentials would be assessed. Several participants also explained that they did not know how to have their prior educational credentials recognized, and whether this was necessary for them to do. This also left some participants with the impression of needing to start over from scratch: "But even if I had high school from back home, I'm told I'm required to do high school from here. I don't know whether it's true, but I just hear from, you know, people, friends who have come from the same place that I have come from. It's like what we started from that side doesn't count."

\section{Study Permits/Immigration}

Several participants reported that they did not have access to information about the relationship between study permits and one's immigration status. There was some confusion about what programs required study permits, as they are not required for English as a Second Language classes and youth secondary school, but are required for refugee claimants and convention refugees looking to attend adult secondary school or post-secondary education. As one participant described it, "The problem was I didn't get the right information before going there [school], because if I knew that I needed a study permit I would have applied way before. But I didn't know that I needed a study permit when I went to that school to apply. I was told I can't start until I get a study permit. So I applied. I'm not sure I'll get in this year because of when I applied. The study permit takes time."

Another participant described how a peer wrongly believed she needed a study permit to access ESL: "She told me she is looking for school because of English. She looked stressed, and then I'm like, 'Why don't you go find one? There are many.' And she said, 'Because I don't have a study permit.' But I think here you can come to do that ESL without a study permit, but not everybody knows about such organizations. That's the biggest problem."

\section{English and Computer Literacy}

Some participants explained they could research information on educational supports, educational programming, and planning their education pathway as a result of their English language skills and computer literacy. One participant reported, "I can understand the language, so if I don't understand something, I can still go online and start to read and help myself."

For several others, a lack of English language and computer skills affected their ability to access information. Participants were dismayed when educational institutions repeatedly pointed them to their websites, after they approached schools for support, as participants found it challenging to navigate the wealth of information on these websites: "If there is something online and it's posted there and you are asking about it, it seems that they will refer to you the website. So, everything is online here, and everything you have to search it by yourself, and it's very detailed, so you are lost. I feel lost."

\section{Financial Aid}

Participants described a general lack of understanding about what types of financial supports could be available to them if they were to attend post-secondary education. This included a lack of information about accessing government loans such 
as OSAP, bursaries, and scholarships, and how these various supports function. One participant noted, "The other thing I want to know is if there are scholarships afforded. As an immigrant landed here, so I'm considered as domestic, not international student, so I want to know if I can have scholarships in the fields I'm applying, and even if I go to the website about scholarships, a lot of options, and I don't know how to proceed."

\section{Impact of Informational Barriers}

As the result of informational barriers and exposure to misinformation, participants reported being disappointed, confused, frustrated, and overwhelmed. They became mistrustful after trying to unsuccessfully access appropriate guidance. Participants often described experiencing a "waste of time" and thought that their educational process was stalled or frozen, because of not getting access to timely and reliable information. One participant explained how misinformation from a legal professional delayed attainment of a study permit, which affected the ability to start schooling in a timely fashion and created a sense of confusion and upset:

So, I couldn't study for three months, I was waiting for the study permit. I didn't know, because I asked a lawyer, and she said, "No you don't need a study permit because you're just doing high school. If you were going to university or something, you do. But because you're doing high school, you don't." And she told me that in July. So, if she had told me the opposite, I could have applied for my study permit in July and have it for September. But because I trusted her very much, so I said, "ok." Then in September when I went to high school, the director, he said, "No you can't, you need a study permit." So, I was like, "I know. But my lawyer told me I don't need." And he's like, "You do." And then I couldn't start. So, it was like I was going from place to place, people telling me different things, and it was just chaos at some point.

\section{Supports}

\section{Need for Individualized Assistance}

Many participants expressed a desire to access a specific trusted support place or person, where they could receive individualized support, to mitigate the informational barriers they experienced in accessing and navigating the educational system. Participants wished they could speak one-on-one to a program administrator at a post-secondary institution, or at other institutions, to understand the prerequisites for programming, and to learn about different avenues for accessing post-secondary education while considering their unique educational history. As one participant described it, "I think I want to have a counsellor who can help me, and test me about where I should be placed. Because I might think I need university, or college, but maybe there is another way that I could reach my goals that I'm not aware of. I'm not sure if it is possible to have education counsellors?"

Participants found it inappropriate to send all refugees to access information online. They suggested having easier access to school administrators to learn about options to students and to mitigate confusion when participants are left to find information on their own.

[I need to know] how to find out about different subjects, and sub-subjects. [I] need for universities to be more accessible with assistance and information. And which field shall I choose, because there are a lot of subspecialties and which is the right track for me. So, I need to communicate with people, with the faculty, with admission. I want them to, if there is an orientation session, let us be aware of them. Instead of "Just go online and read." We need to feel the human flavour, the humanity. We have questions in our mind and we want answers instead of emails because I feel difficult with emails. Why don't we have open doors between the faculty and the immigrant students, sessions to inform them about the subspecialties, about the programs in Canada, so that we can understand the system? Because it looks very complicated for me.

Participants also requested customized and tailored informational support to assist them with filling out school applications, accessing financial aid, obtaining study permits, and other settlement-related needs. They also described the usefulness of emotional support from a service provider, and a better understanding of the support services they could access while in school: "I want somebody to be with me, and ... you know? Keep pushing me, supporting me: 'oK, there it is-this is the map. You can go to that place like this."

\section{Peer Mentorship}

Many participants described how having access to peer mentorship, from newcomers who had similar experiences and challenges, would be a useful source of information. They expected that they would benefit from hearing mentors share stories of how they decided which program to pursue and which institution to attend, how their field of study might enable their job search or security in the future, and their perceptions of what post-secondary education culture is like. Participants also noted that peer mentors could serve as a source of emotional support: "I need somebody like, we are sitting one-to-one, you know? If I face any difficulty in understanding, someone to help me, you know. In homework and this. I need this. 'Cause alone, then I am lost. When I am with somebody, so, it makes me minimize my worries, you know? So, I can go [motions hands in the air, acting out mind drifting] less [referring to trauma, difficulty focusing, and memory loss]." 


\section{Discussion}

The pervasive lack of access to accurate and reliable information experienced by refugees in Canada presents barriers to accessing post-secondary education, along with the social and economic advantages that such access affords. Our findings suggest that many survivors of torture and/or war face challenges in accessing appropriate professional supports and information to navigate educational pathways, and to make informed decisions about what type of post-secondary programs or career training to pursue. Given such lack of resources, refugees often rely on word-of-mouth information, which may not always be trustworthy. Their dilemma is further complicated by the fact that refugees have diverse and unique informational needs, as their immigration statuses, prior credentials and experiences, and specific financial situations all affect the type of information they require to pursue educational goals. Misinformation prolonged their ability to embark on an appropriate educational pathway, thus hindering their timely settlement. These obstacles are troubling, as survivors are often under profound internal and external pressures to secure appropriate employment, which will help them support themselves, and often family who have been left in precarious conditions in their country of origin or in other countries of displacement. These barriers also harm the mental health of survivors, as they often felt frustrated, overwhelmed, and confused by their inability to access appropriate information. This is problematic and concerning, as the mental health and well-being of survivors is already vulnerable, as the result of past trauma as well as the many other structural barriers experienced during resettlement in a new country.

Our findings highlight practical supports that can assist survivors in their educational process. Participants proposed the need for educational support that is tailored to their specific needs, to ensure they receive comprehensive and accurate information. Relying on online information was inadequate for them, because they reported the need in-person guidance from educational institutions or collaborating service providers/agencies to navigate complex intersecting systems, including education, immigration, financial aid, and credential evaluation institutions. These findings support previous research, which demonstrates that educational institutions should provide holistic and comprehensive support, with the input and collaboration of refugees, to respond to their needs and enable their success. For example, Woods has noted that educational institutions should play a role in addressing refugees' complex resettlement issues, to build a sense of community for this population of students. ${ }^{29}$ Woods and Finn have also asserted that educational institutions should acknowledge the impact of past trauma on learning and provide emotional and social support to this community, to heighten educational success. ${ }^{30}$

Survivors also discussed the need to have a human connection during the information-seeking process, to feel supported, encouraged, and confident in their decision-making. They described the potential benefits of having access to peer mentors who were also refugees, who could assist them in navigating educational pathways, inform them of what to expect within post-secondary institutions, and provide tips, support, and inspiration. This is in line with research into how building comprehensive support networks with local staff, faculty, students, and peer mentors can facilitate the effective resettlement and education process for refugees. ${ }^{31}$ It may also be beneficial for refugees to have access to culturally specific peer mentorship, which provides them with information about what structures and behaviours to expect within classrooms. ${ }^{32}$ Furthermore, the potential benefits of peer mentorship for survivors of torture and/or war are supported by research that describes how access to social supports from other refugees can provide insight about how to cope with problems and how to seek formal supports from organizations and government. ${ }^{33}$

\section{Strengths and Limitations}

Limitations of the study include the possibility of response bias and sampling bias. Although all participants were assured of their confidentiality, many survivors live with the psychological after-effects of state-sanctioned violence, which can include the distrust of state or state-related systems. Accordingly, some participants may not have felt comfortable sharing their personal experiences and challenges. Also, even though the research assistants were not associated with CCVT participants may have responded more positively about their experiences accessing post-secondary education because the interviews were located at CCVT, a settlement agency that provides them with support. Conversely, given the participants' sense of trust and comfort with CCVT, it is also possible that participants felt more comfortable sharing their actual experiences. In addition, because the participants involved in the study were survivors who are or have previously been clients of refugee-serving agencies, the sample involved in the study may have been biased in two ways. The sample have missed the survivor population that is not accessing services, and who may face even greater marginalization or barriers to settlement. These may be newcomer survivors in the community who are unaware of services, or who may experience other challenges that limit their involvement, such as family or financial responsibilities, severe mistrust of service providers, or reluctance to "out" themselves as survivors. Alternatively, this study may have oversampled survivors who are experiencing very complex challenges, 
such that they are seeking out services. The participants in the study may then reflect a highly marginalized group of survivors, and other survivors in the community may have the capacity to address barriers to post-secondary education on their own, through appropriate formal networks or other effective methods. Another limitation is that the study did not collect detailed demographic information, which could have also elucidated the findings.

Despite these limitations, the findings of this study are supported by and build on prior research with various refugee communities, concerning challenges they experience in accessing post-secondary education. To our knowledge, this is also the first study of its kind in Canada to partner a postsecondary institution, a mental health and research hospital, and a refugee-serving community organization, and to explore the experiences of refugees in accessing education, collaborating with the study population to create innovative programming that can help bridge the gaps to education that are experienced. These findings of this article have already had practical implications, as they have been integrated into the educational programming created during the second phase of the research project.

\section{Conclusion}

This study expands on previous explorations of the barriers experienced by refugees who try to access higher education and highlights the urgent need for educational institutions and collaborating service providers/agencies to improve access to appropriate supports that mitigate these barriers. The study's findings point to potential areas for improvement across educational institutions, as refugees suggested that access to individualized and holistic supports, and to peer mentorship, could alleviate many of these informational barriers. As examples, educational institutions can enhance their ability to provide individualized support to prospective refugee students by ensuring that their recruitment, entry advisement and registration staff are well trained, knowledgeable, and sensitive to the reality of refugees and their educational resettlement process. Educational institutions can also explore how to improve culturally sensitive and trauma-informed holistic supports to refugee students. This can be accomplished through partnerships between appropriate agencies to provide settlement and mental-health-related services on campus. Drawing on the successes of other mentorship programming within postsecondary institutions, schools could also implement peer mentorship for prospective or new post-secondary refugee students, to enhance their sense of belonging and increase their social support network. Finally, educational institutions can take up the findings in this study to evaluate and modify their policies, procedures, and programs to explore how to enhance their own outreach to refugee communities and how to improve the academic success and experiences of their refugee students.

\section{Notes}

1 Martha Ferede, "Structural Factors Associated with Higher Education Access for First-Generation Refugees in Canada: An Agenda for Research," Refuge 27, no. 2 (2010): 79-88.

2 Kristen Roderick, Rich Janzen, Joanna Ochocka, Anne Westhues, Jenni Jenkins, and Brian Sandbeck, Pathways to Success: Immigrant Youth at High School, (Kitchener, on: Centre for Research and Education in Human Services, 2006); Lori Wilkinson, "Factors Influencing the Academic Success of Refugee Youth in Canada," Journal of Youth Studies 5, no. 2 (2002): 173-93; Maria Yau, "Refugee Students in Toronto Schools," Refuge 15, no. 5 (1996): 9-16.

3 Miles Corak, Age at Immigration and the Educational Outcomes of Children (Ottawa: Minister of Industry, Statistics Canada, 2011).

4 Ferede, "Structural Factors Associated with Higher Education Access"; Navjot K. Lamba, "The Employment Experiences of Canadian Refugees: Measuring the Impact of Human and Social Capital on Quality of Employment," Canadian Review of Sociology and Anthropology 40, no. 1 (2003): 45-64; Don DeVoretz, Sergiy Pivnenko, and Morton Beiser, The Economic Experiences of Refugees in Canada (Burnaby, BC: Vancouver Centre for Excellence, 2004).

5 Morton Beiser and K. Wickrama, "Trauma, Time and Mental Health: A Study of Temporal Reintegration and Depressive Disorder among Southeast Asian Refugees," Psychological Medicine 34 (2004): 899-910; Morton Beiser, Feng Hou, Ilene Hyman, and Michel Tousignant, "Poverty, Family Process, and the Mental Health of Immigrant Children in Canada," American Journal of Public Health 92 (2002): 220-7; Adrienne Wasik, Economic Insecurity and Isolation: Post-Migration Traumas among Black African Refugee Women in the Greater Vancouver Area (Vancouver: Centre of Excellence for Research on Immigration and Settlement-British Columbia Metropolis, 2006).

6 Ferede, "Structural Factors Associated with Higher Education Access."

7 Duncan MacLaren, "Tertiary Education for Refugees: A Case Study from the Thai-Burma Border," Refuge 27, no. 2 (2010): 109.

8 Thomas Crea, "Refugee Higher Education: Contextual Challenges and Implications for Program Design, Delivery, and Accompaniment," International Journal of Educational Development 46, (2016): 12-22; MacLaren, "Tertiary Education for Refugees."

9 Sarah Dryden-Peterson and Wenona Giles, "Introduction: Higher Education for Refugees," Refuge 27, no. 4 (2010): 3-9; Wilkinson, "Factors Influencing the Academic Success of Refugee Youth"; Eileen Pittaway, Chrisanta Muli, and Sarah Shteir. "I Have a Voice-Hear Me!: Findings of an 
Australian Study Examining the Resettlement and Integration Experience of Refugees and Migrants from the Horn of Africa in Australia," Refuge 26, no. 2 (2009): 133-46.

10 Australia's National Research Organisation for Women's Safety Limited, Landscapes: State of Knowledge (Sydney: ANROWS, 2015), https://d2coikyv46o3bi.cloudfront. net/anrows.org.au/s3fs-public/with\%2OLandscapes\%2O final\%20150925.PDF; Diane Drachman, "A State of Migration Framework for Service to Immigrant Populations," Social Work 37, no. 1 (1992): 68-72; "Refugee Status Determination: Identifying Who Is a Refugee," United Nations High Commission for Refugees, 2005, http://www.unhcr .org/publ/pubL/43144dc52.pdf.

11 Hikmet Jamil, Samer Kanno, Rami Abo-Shasha, Mazen AlSaqa, Monty Fakhouri, and Bengt Arnetz, "Promoters and Barriers to Work: A Comparative Study of Refugees versus Immigrants in the United States," New Iraqi Journal of Medicine 8, no. 2 (2012): 19-28.

12 Ibid.; Miriam Stewart, Laura Simich, Morton Beiser, Knox Makumbe, Edward Makwarimba, and Edward Shizha, "Impacts of a Social Support Intervention for Somali and Sudanese Refugees in Canada," Ethnicity and Inequalities in Health and Social Care 4, no. 4 (2011): 186-99; Ransford Danso, "From 'There' to 'Here': An Investigation of the Initial Settlement Experiences of Ethiopian and Somali refugees in Toronto," GeoJournal 56, no. 1 (2002): 3-14; Edward Makwarimba, Miriam Stewart, Laura Simich, Knox Makumbe, Edward Shizha, and Sharon Anderson, "Sudanese and Somali Refugees in Canada: Social Support Needs and Preferences," International Migration 51 no. 5 (2013): 106-19.

13 Linda Morrice, "Journeys into Higher Education: The Case of Refugees in the UK," Teaching in Higher Education 14, no. 6 (2009): 661-72; Ginette Lafrenière and Lamine Diallo, "In the Interest of Working with Survivors of War, Torture and Organized Violence: Lessons from a University/Community Research Collaborative in South-Western Ontario," Canadian Issues Summer (2010): 84-7.

14 Jacqueline Stevenson and John Willott, "The Aspiration and Access to Higher Education of Teenage Refugees in the UK," Compare: A Journal of Comparative Education 37, no. 5 (2007): 671-87; Yogendra Shakya, Sepali Guruge, Michaela Hynie, Arzo Akbari, Mohamed Malik, Sheila Htoo, Azza Khogali, Stella Abiyo Mona, Rabea Murtaza, and Sarah Alley, "Aspirations for Higher Education among Newcomer Refugee Youth in Toronto: Expectations, Challenges, and Strategies," Refuge 27, no. 2 (2010): 65-78.

15 Citizenship and Immigration Canada, "What Are the Language Requirements for the Federal Skilled Worker Program?" last modified 18 April 2017, http://www.cic.gc.ca/ english/helpcentre/answer.asp?qnum $=121 \&$ top $=6$.

16 Walter Renner and Birgit Senft, "Predictors of Unemployment in Refugees," Social Behavior and Personality 41, no. 2 (2013): 263-70; Mary Purkey, "Paths to a Future for Youth in Protracted Refugee Situations: A View from the ThaiBurmese Border," Refuge 27, no. 2 (2010): 97-102.

17 Hetty Roessingh and Scott Douglas, "Educational outcomes of English language learners at university," The Canadian Journal of Higher Education 42, no. 1 (2012): 80-97; Hetty Roessingh and Scott Douglas, "English Language Learners' Transitional Needs from High School to University: An Exploratory Study," Journal of International Migration \& Integration 13 (2012): 285-301.

18 Marina Anselme and Catriona Hands, "Access to Secondary and Tertiary Education for All Refugees: Steps and Challenges to Overcome," Refuge 27, no. 2 (2010): 89-96; Crea, "Refugee Higher Education"; Makwarimba, "Sudanese and Somali Refugees in Canada."

19 Drachman, "State of Migration Framework"; Laurence Kirmayer, Lavanya Narasiah, Marie Munoz, Meb Rashid, Andrew Ryder, Jaswant Guzder, Ghayda Hassan, C. Rousseau, and Kevin Pottie, "Common Mental Health Problems in Immigrants and Refugees: General Approach in Primary Care: Canadian Guidelines for Immigrant Health," Canadian Medical Association Journal 183, no. 12 (2011): 959-66.

20 Katy Robjant, Rita Hassan, and Cornelius Katona, "Mental Health Implications of Detaining Asylum Seekers: Systematic Review," British Journal of Psychiatry 194 (2009): 306-12; Allan Keller, Barry Rosenfeld, Chau Trinh-Shevrin, Chris Meserve, Emily Sachs, Jonathan Leviss, Elizabeth Singer, Hawthorne Smith, John Wilkinson, Glen Kim, Kathleen Allden, and Douglas Ford, "Mental Health of Detained Asylum Seekers," Lancet 362 (2009): 1721-3; Kirmayer, "Common Mental Health Problems in Immigrants and Refugees."

21 Matthew Porter and Nick Haslam, "Predisplacement and Postdisplacement Factors Associated with Mental Health of Refugees and Internally Displaced Persons: A Metaanalysis," Journal of the American Medical Association 294 (2005): 602-12; Ilene Hyman, Morton Beiser, and Nhi Vu, "The Mental Health of Refugee Children in Canada," Refuge 15 (1996): 4-8; Michel Tousignant, "The Quebec Adolescent Refugee Project: Psychopathology and Family Variables in a Sample from 35 Nations," Journal of the American Academy of Child and Adolescent Psychiatry 38, no. 11 (1999): 1426-32; Haile Fenta, Ilene Hyman, and Samuel Noh, "Determinants of Depression among Ethiopian Immigrants and Refugees in Toronto," Journal of Nervous and Mental Disease 192 (2004): 363-72.

22 Mulugeta Abai and Lydia Sawicki, "Toward a Community Based Approach to Healing: A Case Study of the Canadian Centre for Victims of Torture," Refuge 15 (1997): 32-3; Thomas Campbell, "Psychological Assessment, Diagnosis, and Treatment of Torture Survivors: A Review," Clinical Psychology Review 27 (2007): 628-41; J. David Kinzie, "The Effects of War: A Comparison of Somali and Bosnian Refugee Psychiatric Patients" (paper presented at World Association of Cultural Psychiatry's 2nd World Congress, Norcia, 
Italy, 2009); Kinzie, "Guidelines for Psychiatric Care of Torture Survivors," Torture 21 (2011): 18-26.

23 Anita Ramaliu and Wilfreda Thurston, "Identifying Best Practices of Community Participation in Providing Services to Refugee Survivors of Torture: A Case Description," Journal of Immigrant Health 5 (2003): 165-72; Metin Basoglu, "Rehabilitation of Traumatized Refugees and Survivors of Torture," British Medical Journal 333, no. 7581 (2006): 1230-31; Gerald Gray, "Treatment of Survivors of Political Torture: Administrative and Clinical Issues," Journal of Ambulatory Care and Management 21 (1998): 39-55; Kelly McKinney, "Culture, Power, and Practice in a Psychosocial Program for Survivors of Torture and Refugee Trauma," Transcultural Psychiatry 44 (2007): 482-503; Ann Marie Winter, "Social Services: Effective Practices in Serving Survivors of Torture," Torture 21 (2011): 48-55.

24 Lawrence Green, M. Anne George, Mark Daniel, C. James Frankish, Carol Herbert, William Bowie, and Mitchel O'Neill, Study of Participatory Research in Health Promotion: Review and Recommendations for the Development of Participatory Research in Health Promotion in Canada (Vancouver: Royal Society of Canada, 1995).

25 Michael Patton, Qualitative Research and Evaluation Methods, 3rd ed. (Thousand Oaks, CA: Sage, 2002).

26 John W. Creswell, Qualitative Inquiry and Research Design: Choosing among Five Approaches, 2nd ed. (Thousand Oaks, CA: Sage, 2007).

27 Ibid.

28 Melanie Birks, Ysanne Chapman, and Karen Francis, "Memoing in Qualitative Research Probing Data and Processes," Journal of Research in Nursing 13, no. 1 (2008): 68-75; Patton, Qualitative Research and Evaluation Methods.

29 Annette Woods, "Learning to Be Literature: Issues of Pedagogy for Recently Arrived Refugee Youth in Australia," Critical Inquiry in Language Studies 6, no. 1 (2009): 81-101.

30 Ibid.; Heather Finn, "Overcoming Barriers: Adult Trauma Survivors in a Learning Community," TESOL Quarterly 44, no. 3 (2010): 586-96.

31 Glen Peterson, "Education Changes the World': The World University Service of Canada's Student Refugee Program," Refuge 27, no. 2 (2010): 111-21; Eliana Hirano, "Refugees in First Year College: Academic Writing Challenges and Resources," Journal of Second Language Writing 23 (2014): $37-52$.
32 Ilene Hyman, Nhi Vu, and Morton Beiser, "Post-Migration Stresses among Southeast Asian Refugee Youth in Canada: A Research Note," Journal of Comparative Family Studies 31, no. 2 (2000): 281-93.

33 Laura Simich, Morton Beiser, and Farah Mawani, "Social Support and the Significance of Shared Experience in Refugee Migration and Resettlement," Western Journal of Nursing Research 25, no. 7 (2003): 872-91; Stewart et al., "Impacts of a Social Support Intervention"; Miriam Stewart, Joan Anderson, Morton Beiser, Edward Makwarimba, Anne Neufeld, Laura Simich, and Denise Spitzer, "Multicultural Meanings of Social Support among Immigrants and Refugees," International Migration 46, no. 3 (2008): $123-59$.

Jaswant Kaur Bajwa is a professor and research lead in the Centre for Preparatory \& Liberal Studies at George Brown College. The author may be contacted at jkaur@georgebrown .ca.

Sidonia Couto is a registered social worker and worked with the Canadian Centre for Victims of Torture at the time of this research. The author can be contacted at sidonia_o1@hotmail .com.

Sean Kidd is a clinical psychologist and clinician scientist at the Centre for Addiction and Mental Health. The author can becontacted atsean.kidd@camh.ca.

Roula Markoulakis is a research assistant at Sunnybrook Health Sciences Centre. She worked at George Brown College to support this research. She can be contacted at roula .markoulakis@sunnybrook.ca.

Mulugeta Abai is the executive director of the Canadian Centre for Victims of Torture. The author can be reached at mabai@ccvt.org.

Kwame McKenzie is the CEO of the Wellesley Institute and a psychiatrist with the Centre for Addiction and Mental Health. The author can be reached at kwame@wellesleyinstitute.com. 